\title{
Application of Portfolio Evaluation in Business Basic Japanese Teaching
}

\author{
Lei $\mathrm{Xu}$ \\ Dalian Neusoft University of Information \\ Dalian, China 116023
}

\begin{abstract}
Along with the deepening of the reform of higher education, the basis of evaluation of educational teaching is changing. The evaluation method of portfolio in process evaluation is widely concerned and popularized by scholars both at home and abroad. On the basis of expounding the basic connotation and theoretical basis of portfolio evaluation, this paper explores the application of portfolio evaluation in the business basic Japanese teaching. It is divided into the introduction of file bags and portfolio evaluation, the establishment of learning objectives, portfolio evaluation criteria, the clear collection of content, the determination of the frequency of portfolio display and evaluation, personal reflection four parts. At the same time, the paper further explores the Enlightenment of portfolio evaluation on business basic Japanese teaching.
\end{abstract}

Keywords-file bag evaluation; reflection; self-study; Business Basic Japanese

\section{INTRODUCTION}

With the deepening of the reform of higher education in our country, the basis of evaluation of educational teaching has been changed. From the traditional focus on the examination of students to obtain the amount of selected knowledge of teachers, transferred to the examination of students to use the knowledge obtained by [1]. Under such educational background, the portfolio evaluation which pays attention to process evaluation has received extensive theoretical attention and practice promotion.

In the process of carrying out portfolio evaluation, students not only accept the evaluation passively, but also take the initiative to participate in the process of the evaluation content and standard, and reflect on their own learning quality. Due to the advanced nature of its evaluation concept, portfolio evaluation has been widely applied and popularized in the field of foreign language education in Europe and the United States, Canada, Britain and France since the last century 90. 2001, portfolio evaluation was introduced into Japan's "comprehensive education" curriculum. Based on the "European Language education common platform", CEFR, Japan International Exchange Foundation, which lasted 5 years, studied and developed a set of reference standards for Japanese education - [JF Japanese Education Standard 2010] learning and evaluation in 2010. Nowadays, portfolio evaluation has become an important method in the evaluation of Japanese education.
Application-oriented business Japanese talent is a new requirement for Japanese talents in the new era. The Business basic Japanese course, which occupies a very high proportion of the school hours in the practical business Japanese Talent training program, is an important basis for the cultivation of applied talents. Among them, the setting of evaluation standard is the important part of deciding teaching direction and content. Traditional evaluation, lack of monitoring of learners' learning process, cannot show the students' learning effect comprehensively and objectively, the traditional evaluation, the learner blindly passively accepts, does not have the time and the experience to introspect to the study process and adjusts own learning strategy, does not favor the student main body consciousness, the inquiry spirit and the independent study ability training. Therefore, it can be said that to meet the above conditions of the portfolio evaluation is a useful supplement to the traditional evaluation methods.

\section{The BASic ConNotation OF Two PoRtFolio EVALUATION}

For the portfolio evaluation, different scholars have different sayings, according to the previous research results can be summed up portfolio evaluation: is to collect and record the students for a period of time of learning results, to test the learning progress of students and learning achievement evaluation methods. Portfolio evaluation is different from traditional evaluation method, and it is a comprehensive evaluation system which integrates authenticity evaluation, qualitative evaluation, developmental evaluation and multiple evaluation concept and method.

Based on the above summary of the definition of portfolio evaluation, it can be said that in the evaluation process of portfolio, students are no longer passive acceptance of evaluation, but actively participate in the selection of works, and through self-evaluation and mutual evaluation of the content of the evaluation of the continuous reflection. At the same time, students will also participate in the creation of portfolio and grading standards.

According to the difference of evaluation subject and evaluation method, portfolio evaluation can be divided into file type, display type, evaluation type, process type and compound portfolio evaluation [2]. 
Among them, the document type has little relation with the student, its main participant is the teacher, and the other four types can help the student to reflect through the file bag, all relate to the student. As far as the main body of evaluation is concerned, the evaluation-type portfolio is mainly based on his comments, while the process-oriented portfolio pays more attention to the process of students ' selfevaluation and self-development [3]. Compound file bag is a combination of the above several file bags. It would include: The work that the student chooses, the work which the teacher chooses, the appraisal tool. Collecting students' study works and prompting them to reflect positively, record the growth process of students, evaluate the students' important learning results; learn the course of classroom teaching and report to others. The portfolio evaluation in foreign language teaching generally refers to the compound file bag.

The rise of portfolio evaluation is related to many factors. Among them, the theory of multiple intelligences and constructivist learning is the important theoretical basis of portfolio evaluation. The theory of multiple intelligences is an educational theory put forward by American psychologist Gardner, who believes that human intelligence is composed of many factors and is pluralistic. Therefore, the evaluation of learners can not only be the assessment of learning results, but should be personalized and diverse. Constructivist learning theory holds that knowledge is not taught by teachers, and the second is that students build and acquire them in the process of mutual cooperation under certain social and cultural backgrounds. It can be said that the above theoretical basis and portfolio evaluation emphasizes that learners are the main body of evaluation, and the principal position of learners in the process of evaluation is consistent.

\section{APPLICATION OF PORTFOLIO EVALUATION IN BUSINESS BASIC JAPANESE TEACHING}

With advanced educational concept, the Portfolio evaluation method has been widely used in two language acquisition and foreign language teaching at home and abroad. It can be said that the application of foreign portfolio evaluation in teaching practice and the positioning of the portfolio evaluation in Japan's JF Japanese Education Implementation Standard provide reference for the reform of foreign language education evaluation in China. But at present, the application of portfolio evaluation method in foreign language teaching in China is still rare, and its research results mainly focus on English teaching practice. How to effectively apply portfolio evaluation to Japanese teaching is a subject worthy of exploration and research.

The following is the "business base Japanese (ii)" Course of the first year of the University (second) curriculum [use of the textbook: "The Basic Japanese (second volume)]" [4] For example, according to the following steps, the implementation of the portfolio evaluation method is specified.

\section{A. Introduction of File Bags and Portfolio Evaluation}

The principle of portfolio evaluation is the evaluation method which is carried out under the precondition of the learners' full understanding of the portfolio and portfolio evaluation. Therefore, in this semester the first class, first to introduce students to the portfolio evaluation and its significance. It emphasizes that portfolio evaluation, as a formative assessment, promotes the learners ' learning effect, makes students accept this new form of evaluation subjectively, and mobilizes the enthusiasm and enthusiasm of students to collect portfolio evaluation content. Then instruct students to choose appropriate containers (such as file boxes, folders, etc.) to make file bags, and on the cover of Professional, grade, student number, name and other personal basic information and file bag directory for easy access.

\section{B. Developing Learning Objectives, Portfolio Evaluation Criteria, and Clear Collection of Content}

One of the characteristics of portfolio evaluation is that students are no longer passively accepted for evaluation, but as decision makers of evaluation criteria and content. In combination with the curriculum syllabus of basic Business Japanese (ii) and the actual situation of the students, the teacher first set the learning objectives and portfolio evaluation criteria, and then in the classroom to allow students to fully discuss and jointly modify, formulate specific learning goals and easy to operate evaluation criteria. At the same time, teachers and students jointly determine the material to be collected in the file bag and the scores of each part of the material. "Basic Business Japanese (ii)" contains nine lessons, according to the content of the nine lessons will be divided into three units. First of all, to guide students in accordance with each lesson as a unit, to build bags, each of the small bags of materials including preview problem table, self-assessment and teacher evaluation table, vocabulary grammar quiz, wrong title record, learning experience and reflective table. Second, to guide students to build bags in units, each unit of the small bag materials including the Unit project context of the first draft, revised manuscript and peer review feedback, unit learning log, self-assessment and mutual assessment form. Third, the portfolio will also be included in the midterm, final results of the evaluation of self-evaluation and teacher evaluation. Students can also be put into the ability to reflect the characteristics of personal materials, such as reading contests, situational dialogue performance, composition contest paper materials, video and so on.

\section{Determination of Frequency and Presentation of Portfolio Evaluation}

Presentation and evaluation is a very important part of portfolio evaluation. The Business basic Japanese (ii) course contains three modules. According to the curriculum, each unit after the end of the course has a unit of knowledge Review class, review of the content of the course by the teacher with the contents of the learning content of flexible master, and to make appropriate additions. After discussion with the students, decided to take each unit review course as a portfolio evaluation and display time, that is, each unit once, a total of three times a semester. Students to each other to circulate their own display materials, exchange of learning experience and experience. Teachers guide students to 
evaluate the contents of the portfolio according to the evaluation criteria. Teachers in the evaluation process, encourage students to learn from each other, and further stimulate students to collect file bag material enthusiasm. After the self-assessment, the mutual evaluation, the students hand in the file bag material, the teacher unifies each schoolmate's file bag material content, gives the personalized, has the pertinence comprehensive appraisal opinion, so that the student understands one's insufficiency in time, and directs the direction for the student follow-up effort.

\section{Personal Learning and Reflection}

Reflection is the most important link in the process of portfolio evaluation, and it is an important factor distinguishing from the general work set. The evaluation of portfolio can promote learners ' learning strategies and their reflection on learning process, which is the process of selfmonitoring and self-development. Therefore, the role of teachers in this link should not be overlooked. Teachers should not only guide students to evaluate their peers objectively and impartially, but also accept others' evaluation and teachers ' feedback. Through the study of reflection to understand the shortcomings of individuals, and improve measures. For example: This unit learned what knowledge, whether to achieve the intended learning goals, how to improve learning methods. Through the study and reflection, students can adjust their learning methods and strategies according to their own problems, so as to promote the learning effect.

\section{The REVElation of Portfolio EVAluation to BUSINESS BASIC JAPANESE TEACHING}

\section{A. Conducive to the Full Display of Learning Effects}

Compared with traditional evaluation methods, portfolio evaluation lays stress on students ' efforts and is a continuous record of students ' progress in learning. Therefore, it is the evaluation of dynamic, continuous and development. The characteristics of learning motivation, will, methods and creativity that are often neglected in the process of language learning are valued in portfolio evaluation. Foreign language learning is a discipline that attaches importance to the process, and the lack of process is bound to influence the cultivation of ability. Portfolio evaluation is to make up for the traditional lack of process evaluation of the drawbacks, a true and comprehensive record of the student learning process. At the same time, the record contents of portfolio evaluation can provide some reference for the teachers who follow the course to understand the students ' learning effect.

\section{B. Help to Improve the Ability of Autonomous Learning}

Portfolio evaluation is under the guidance of teachers, students choose their own material content, and actively participate in the formulation of learning objectives and evaluation criteria. This has fully mobilized students' enthusiasm and improved self-management ability. In the evaluation process, in addition to teacher evaluation, as well as the students as the subject of self-assessment and peer review, through self-evaluation and profound study of reflection, can cultivate student's critical thinking and innovative ability, and gradually form self-evaluation, selfreflection ability. Secondly, the most important thing of portfolio evaluation is to enable students to learn from the closed-closed test to improve their comprehensive ability, students are no longer passively to complete the task of learning, but actively participate in the teaching process, so as to form a good habit of independent learning.

\section{Facilitate Communication between Teachers and Students}

Communication is an effective way to promote language learning, and portfolio evaluation can effectively promote the communication between teachers and students and peers while enriching the evaluation methods. Business Japanese teaching in the classroom time is limited, students can use the class time, through the collection of archival materials, and peer exchange learning experience and methods, and teachers to explore learning problems, so as to effectively promote Japanese learning. In the process of self-evaluation, peer review and teacher evaluation, students can learn from each other by evaluating each other's learning status. Through evaluation, teachers can understand the application of knowledge and existing problems, so as to adjust the teaching methods in order to achieve the best teaching results.

\section{CONCLUSION}

The portfolio evaluation has been widely applied and popularized in foreign language teaching practice. In China, the purpose of portfolio evaluation is consistent with the training target of business Japanese, which is a useful supplement to the traditional evaluation method, and also provides a new way for business Japanese teaching evaluation reform. The exploration and practice of the portfolio evaluation in the Business basic Japanese course has effectively mobilized the students ' enthusiasm in Japanese learning and promoted the learning effect. However, the portfolio evaluation method still faces many problems in the course of teaching implementation. For example, the objectivity and impartiality of some evaluation criteria are difficult to guarantee; Teachers lack the relevant experience of portfolio evaluation; file bag evaluation is timeconsuming and laborious, occupying a lot of time and energy of teachers and students. Not suitable for a number of courses at the same time to carry out such evaluation methods. How to make use of portfolio evaluation more scientifically and effectively to serve business Japanese teaching requires further theoretical research and practical exploration.

\section{REFERENCES}

[1] Wan Wei, Qin Delin, Wu Yongjun. Educational evaluation method and design [M]. Beijing: Education Science Press, 2005.

[2] Hu Zhongfeng, Lie Qun. Reflection on students ' portfolio evaluation [J]. Curriculum teaching Methods, 2006 (10): 34-40.

[3] Liu Guiqiu. The theory and practice of College English Portfolio evaluation $[\mathrm{J}]$. Journal of Shenyang Normal University (social Science edition), 2011 (06): 176-179. 
[4] Yoshioka and others. Standard Business Japanese (volume II) [M]. Foreign language teaching and research press. 2010. 